\title{
NEW LIQUID CRYSTALS IN THE SERIES OF 1, 3, 5-TRIAZINE COMPOUNDS CONTAINING AZOBENZENE AT THE PERIPHERAL ARMS
}

\author{
A. A. Salisu ${ }^{1 *}$ and A. A Kogo ${ }^{2}$ \\ ${ }^{1}$ Department of Pure and Applied Chemistry, Bayero University Kano, P. M. B.3011 Kano, Nigeria \\ ${ }^{2}$ Department of Textile Science and Technology, Ahmadu Bello University Zaria, Kaduna, Nigeria \\ *Correspondence author: aasalisu@yahoo.com
}

\begin{abstract}
Novel liquid crystal materials whose molecular structures consist of disc-like 1,3,5-triazine unit as a central core and three rod-like azobenzenes as the peripheral arms unit has been prepared and characterized by spectroscopic methods, and X-ray diffraction. The Series of compounds were prepared by nucleophilic addition of the primary amino nucleophile to 1,3,5-triazine electrophilic ring via alkyl spacers in presence of potassium carbonate as hydrochloride acceptor. Differencial scanning calorimetry (DSC), polarizing optical microscopy and $x$-ray diffraction confirmed Smectic mesophase textures of the materials. Increase in the polymethylene spacer length influence the thermal and phase stability of the compounds studied.
\end{abstract}

Keywords: Liquid crystal, azobenzene, Smectic mesophase, triazine core, discotic

\section{INTRODUCTION}

One approach towards oligomeric mesogens with a well defined molecular structure just bridging the gap between monomeric and polymeric mesogens consists in the chemical linkage of a defined number of formed anisotropic sub-units [Kouwer et al.2003]. Beside various dimeric mesogens appropriate trimers and tetramers are available by connecting three or four mesogenic groups with a central linking unit. Examples are tetrameric liquid crystals with biphenyl and phenylcyclohexyl groups linked to tetrahedral penta-erythritol unit [Goldman et al. 1998], photochromic star-like siloxane liquid crystal incorporating four butoxyazobenzene mesogens in its periphery [Liu et al. 2005], Star-shaped glassy liquid crystals containing pentaerythritol as flexible core and $\omega$-[4-(p-alkoxybenzoloxy)phenoxycarbonyl] valeric acid as side mesogenic arms (Liu et al.2005 and zhang et al. 2005).

On one hand, there has been much interest in the synthesis and characterization of compounds containing a 1, 3, 5-triazine unit owing to their interesting properties, such as liquid crystalline and non linear optical properties as well as their applications in other fields [Lee et al. 2002] . Among these materials, disc-like liquid crystals are particularly gathering attention especially, with respect to their unique optical properties. More recently a 1,3 , 5triazine has been used as a core [Lee et al. 2002, Lee et al.2001 and Lee et al. 2004). In addition, from the synthetic view point, the mesogenic $1,3,5$-triazine compounds have an advantage. Various nucleophilic side groups have been easily incorporated with the triazine ring by their reaction with cyanuric chloride, showing discotic as well as calamitic morphological behaviors depending on their structures (Lee et al. 2001). It has been demonstrated that the 1,3,5triazine ring is a suitable structural element to be incorporated into thermotropic liquid crystals thus, aromatic esters involving 1,3,5-triazine moiety were found to exhibit calamitic mesophases (Goldmann et al. 1998). A series of 2,4,6-triarylamino-1,3,5-triazines bearing six long peripheral alkoxy chains which form enantiotropic columnar mesophases were reported, although the molecules are characterized by a lack of inherent molecular planarity. Goldmann et al. (1981) attached three rod-like alkoxy subtituited azobenzenes molecular sub-units to the 2-, 4- and 6-positions of the 1,3,5-triazine nucleus via secondary amino linkages. These compounds are considered as calamitic homotrimers with a 1,3,5-triazine core as the central linking unit exhibiting nematic phase on cooling from the isotropic phase and upon cooling the nametic phases, forcal-conic fan shape textures developed for some of the compounds [Goldmann et al. 1998]. Therefore, the question of new molecular design arises as how to modify the substitution pattern of the 1,3,5-triazine ring in such away that liquid crystalline compounds result, probably exhibiting highly ordered Smectic phases. Our approach therefore, consists in attaching three rod-shaped azobenzene molecular sub-units via alkyl spacers to 24- and 6-positions of the triazine nucleus via secondary amino linkages (Scheme 1). Herein, the series of these compounds are presented.

\section{MATERIALS AND METHODS}

All materials are of analytical grade unless otherwise stated. 4-Aminoacetophenone (Fluka), Sodium nitrite $(\mathrm{BDH})$, Urea (BDH), Phenol (Merck), a, $\omega$ dibromoalkanes (Fluka), potassium carbonate (Fluka), potassium hydroxide (Hamberg), ethanol amine (Acros), potassium carbonate (Fluka) and Cyanuric chloride (Acros) were used without further purification. Dry acetone, dry butanone and dry tetrahydrofuran (THF) were obtained from distilling over phosphorous pentoxide (Merck). 
Other solvents and chemicals were used also without further purification. Silica gel 60 (230-460nm) was used for column chromatography. FT-IR spectra were measured on a BX spectrum II FT-IR spectrometer (Perking Elmer). ${ }^{1} \mathrm{H}$ NMR spectra $(400 \mathrm{MHz})$ were recorded on a Jeol ECA 400 NMR spectrometer (Jeol, Japan). Phase transition temperatures and thermodynamic parameters were determined by using a DSC 7 (Perkin Elmer) and DSC 8 (diamond DSC. Perkin Elmer) equipped with a liquid nitrogen cooling system under nitrogen atmosphere. The heating and cooling rates were $10^{\circ} \mathrm{C} \mathrm{min}^{-1}$. Phase transition temperatures were collected during the second heating and the second cooling scans. An Olympus (Leica, Germany) polarizing optical microscope equipped with a Linkam THMSE-600 (Linkam, England) hot stage was used to observe phase transition temperatures and optical textures to analyze liquid crystal properties of the new material. The XRay measurement was performed using a nickelfiltered $\mathrm{Cu}-\mathrm{K}_{1}$ radiation with a Philips X-Ray diffractometer X'PERT PRO PW 3040 (PanAnalytical, Holland).

\section{RESULTS AND DISCUSSION}

\section{Synthesis}

Scheme 1 illustrates the structures and the synthetic route to the 1,3,5-triazine compounds. The peripheral arm units of the mesogenic part for all the compounds studied were prepared by diazotization of 4Aminoacetophenone and then coupling of diazonium salt, with phenol yielding 4-(4acetophenonephenylazo)phenol $\mathbf{2}$.

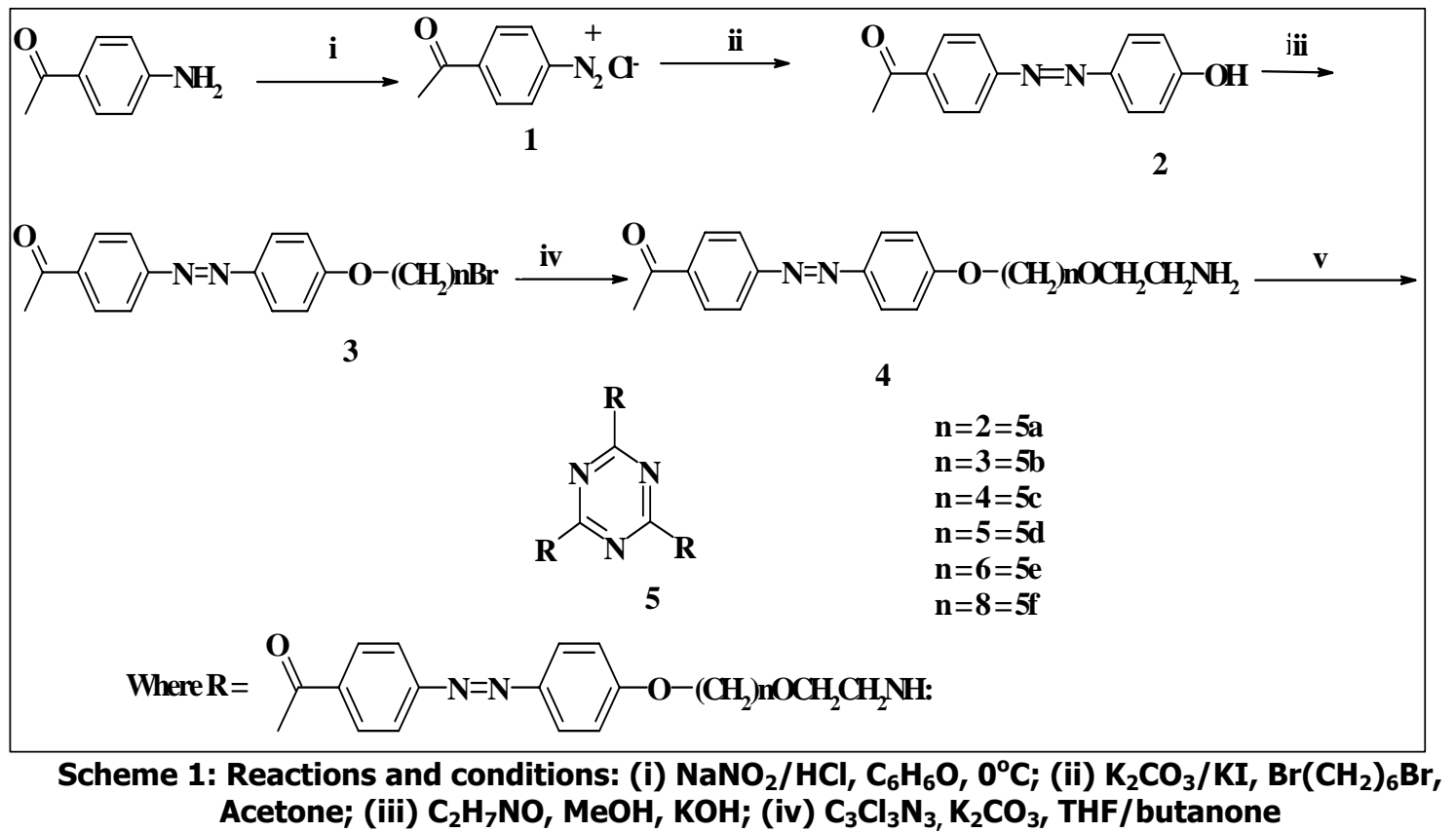

The flexible spacers were introduced by alkylation of phenol 2, with a 10-fold excess of appropriate dibromoalkane in the presence of potassium carbonate as base to give 1-bromo-4-(4acetylphenylazo)phenoxyalkane $\mathbf{3}$ according to reported literature procedure[Lutfor et al. 2005, Lutfor et al. 2007]. Compound 3 was further alkylated with ethanolamine by Williamson's ether synthesis reaction to produce 4-(4acetylphenylazo)phenoxyalkoxylethylamine 3. Finally, a disc-like molecule 2,4,6-tris-4-(4acetylphenylazo)phenoxyalkoxylethylamine-1,3,5triazine $\mathbf{4}$ was produced by nucleophilic addition of the primary amino nucleophile to 1,3,5-triazine electrophilic ring in presence of potassium carbonate as hydrochloride acceptor (Scheme 1). A general procedure for compound $\mathbf{4}$ and $\mathbf{5 d}$ is given as described in the previous paper [A. A. Salisu, 2008]. 4-(4-acetylphenylazo)phenoxyhexyloxyethylamine 4 A mixture containing compound $3(2.00 \mathrm{~g}, 4.9 \mathrm{mmol})$, ethanolamine $(0.302 \mathrm{~g}, 4.9 \mathrm{mmol})$, and potassium hydroxide $(0.274 \mathrm{~g}, 4.9 \mathrm{mmol})$ were refluxed for $10 \mathrm{~h}$ under nitrogen atmosphere with stirring in methanol $(180 \mathrm{ml})$. The reaction mixture was allowed to cool down to room temperature, then poured into ice-cold water and acidified with dilute hydrochloric acid. The resulting yellowish precipitate, was collected by filtration and recrystallized from methanol. Yield $1.86 \mathrm{~g}$ (86\%), m.p. $=105-107{ }^{\circ} \mathrm{C}$. FT-IR, $\left(\mathrm{KBr}, \mathrm{cm}^{-1}\right): 2938$, $2862(\mathrm{C}-\mathrm{H}, \mathrm{U}), 1674(\mathrm{C}=\mathrm{O}, \mathrm{U}), 1598,1498,1470$ (aromatic, U), $1396(\mathrm{C}-\mathrm{H}, \delta), 1358(\mathrm{OH}, \delta), 1188(\mathrm{C}-$ $\mathrm{O}-\mathrm{C}, \mathrm{U}), 1254,1126(\mathrm{C}-\mathrm{H}, \delta), 842$ (aromatic, $\delta) .{ }^{1} \mathrm{H}$ NMR, $\left(400 \mathrm{MHz} \mathrm{CDCl}_{3}\right), \delta: 8.08(2 \mathrm{H}, \mathrm{d}, \mathrm{J}=8.2 \mathrm{~Hz}$, ArH), $7.93(4 \mathrm{H}, \mathrm{d}, \mathrm{J}=8.7 \mathrm{~Hz}, \mathrm{~d}, \mathrm{~J}=5.8 \mathrm{~Hz}, \mathrm{ArH}), 7.02$ $(2 \mathrm{H}, \mathrm{d}, \mathrm{J}=8.9 \mathrm{~Hz}, \mathrm{ArH}), 4.06(2 \mathrm{H}, \mathrm{t}, \mathrm{J}=6.4 \mathrm{~Hz}$, $\left.\mathrm{OCH}_{2}\right), 3.44\left(2 \mathrm{H}, \mathrm{t}, \mathrm{J}=5.2 \mathrm{~Hz}_{1} \mathrm{OCH}_{2}\right), 2.66(3 \mathrm{H}, \mathrm{s}$, $\left.\mathrm{CH}_{3}\right), 1.93-1.84\left(4 \mathrm{H}, \mathrm{m}, \mathrm{CH}_{2}\right) 3.58(2 \mathrm{H}, \mathrm{m}, \mathrm{N}-\mathrm{H})$. 
3.3 acetylphenylazo)phenoxyhexyloxyethylamine-1,3,5triazine $\mathbf{5}$

A mixture consisting of a solution of compound $\mathbf{4}$ $(1.5 \mathrm{~g}, 3.91 \mathrm{mmol})$ in dry butanone $(80 \mathrm{ml})$, cyanuric chloride $(0.239 \mathrm{~g}, 1.30 \mathrm{mmol})$ and potassium carbonate $((0.539 \mathrm{~g}, 3.91 \mathrm{mmol})$ were refluxed for 24 $\mathrm{h}$ under nitrogen atmosphere. The reaction mixture was brought to the room temperature, poured into ice-cold water and acidified with dilute hydrochloric acid. The resulting precipitate was collected by sunction filtration and recrystallized twice from methanol and ethanol respectively. Yield: $0.762 \mathrm{~g}$ (24\%) m. p. $=95-97^{\circ} \mathrm{C}$. FT-IR $\left(\mathrm{KBr}, \mathrm{cm}^{-1}\right): 2938,2862$ $(\mathrm{C}-\mathrm{H}, \mathrm{U}), 1674(\mathrm{C}=\mathrm{O}, \mathrm{U}), 1598,1498,1470$ (aromatic, U), $1396(\mathrm{C}-\mathrm{H}, \delta), 3076(\mathrm{~N}-\mathrm{H}, \mathrm{U}) 1188(\mathrm{C}-\mathrm{O}-\mathrm{C}, \mathrm{U})$, 1254, $1126(\mathrm{C}-\mathrm{H}, \delta), 842$ (aromatic, $\delta) .{ }^{1} \mathrm{H}$ NMR, $\left(600 \mathrm{MHz}, \mathrm{CDCl}_{3}\right), \delta: 8.08(2 \mathrm{H}, \mathrm{d}, \mathrm{J}=8.2 \mathrm{~Hz}, \mathrm{ArH})$, $7.93(4 \mathrm{H}, \mathrm{d}, \mathrm{J}=8.7 \mathrm{~Hz}, \mathrm{~d}, \mathrm{~J}=5.8 \mathrm{~Hz}, \mathrm{ArH}), 7.02(2 \mathrm{H}$, $\mathrm{d}, \mathrm{J}=8.9 \mathrm{~Hz}, \mathrm{ArH}), 4.06\left(2 \mathrm{H}, \mathrm{t}, \mathrm{J}=6.4 \mathrm{~Hz}, \mathrm{OCH}_{2}\right)$, $3.44\left(2 \mathrm{H}, \mathrm{t}, \mathrm{J}=5.2 \mathrm{~Hz}, \mathrm{OCH}_{2}\right), 2.66\left(3 \mathrm{H}, \mathrm{s}, \mathrm{CH}_{3}\right)$, 1.93-1.84 (4H, m, $\left.\mathrm{CH}_{2}\right), 7.02(3 \mathrm{H}, \mathrm{m}, \mathrm{N}-\mathrm{H})$. Elemental analysis: calculated for $\mathrm{C}_{69} \mathrm{H}_{84} \mathrm{~N}_{12} \mathrm{O}_{9}$ (1225.51) C, $69.63 \% ; \mathrm{H}, 6.91 \% ; \mathrm{N}, 13.75 \%$. Found $\mathrm{C}, 67.42 \% ; \mathrm{H}$, $6.72 \% ; \mathrm{N}, 13.83 \%$.

\section{Phase transitions}

The phase transition temperatures as well as the phase transition enthalpy changes were determined using differential scanning calorimetry (DSC) and the result of the second heating and cooling scans are summarized in table 1 . Compounds with short to medium spacer length $\mathbf{5} \mathbf{a}-\mathbf{5 e}\left(\mathrm{C}_{2}-\mathrm{C}_{6}\right)$ exhibited an enantiotropic smectic $A$ mesophases while, compound $\mathbf{5 f}\left(\mathrm{C}_{8}\right)$ possessed a monotropic phase on cooling from the isotropic liquid as shown in table 1 . The clearing temperatures decrease with increase in spacer length for the compounds studied. These materials are very stable crystals at room temperature.

Table 1: Phase transition temperatures and enthalpies obtained from DSC scans.

\begin{tabular}{|c|c|c|}
\hline Compound & $\mathbf{n}$ & $\begin{array}{l}\text { Transition temperature }(T / C) \text { and associated } \\
\text { Transition enthalpies values }\left(\Delta H / J K^{1}\right) \text {, heating/cooling }\end{array}$ \\
\hline $5 a$ & & $\mathrm{Cr} 68.70$ (57.8) SmA 96.80 (3.6) I 78.79 (6.7) SmA 42.56 (22.6) $\mathrm{Cr}$ \\
\hline $5 b$ & 3 & Cr 73.39 (39.7) SmA 102.24 (11.9) I 92.24 (34.1) SmA $46.73(28.3) \mathrm{Cr}$ \\
\hline $5 c$ & 4 & Cr 79.32 (46.3) SmA 109.26 (1.9) I $98.72(7.8) \mathrm{SmA} 49.8$ (46.2) Cr \\
\hline $5 d$ & 5 & Cr 75.88 (53.3) SmA 103.19 (0.6) I 87.66 (7.9) SmA 42.09 (31.2) Cr \\
\hline $5 e$ & 6 & Cr 91.92 (66.75) SmA 107.69 (2.5) I 102.99 (8.69) SmA64.39 (49.5)Cr \\
\hline $5 f$ & 8 & $\mathrm{Cr} 98.66(78.7)$ I $90.20(1.23) \mathrm{SmA} 69.98(57.4) \mathrm{Cr}$ \\
\hline
\end{tabular}

${ }^{\mathrm{a}}$ Abbreviations: $\mathrm{Cr}=$ crystal, $\mathrm{SmA}=$ smectic $\mathrm{A}, \mathrm{I}=$ isotropic phase, transition enthalpies in parenthesis

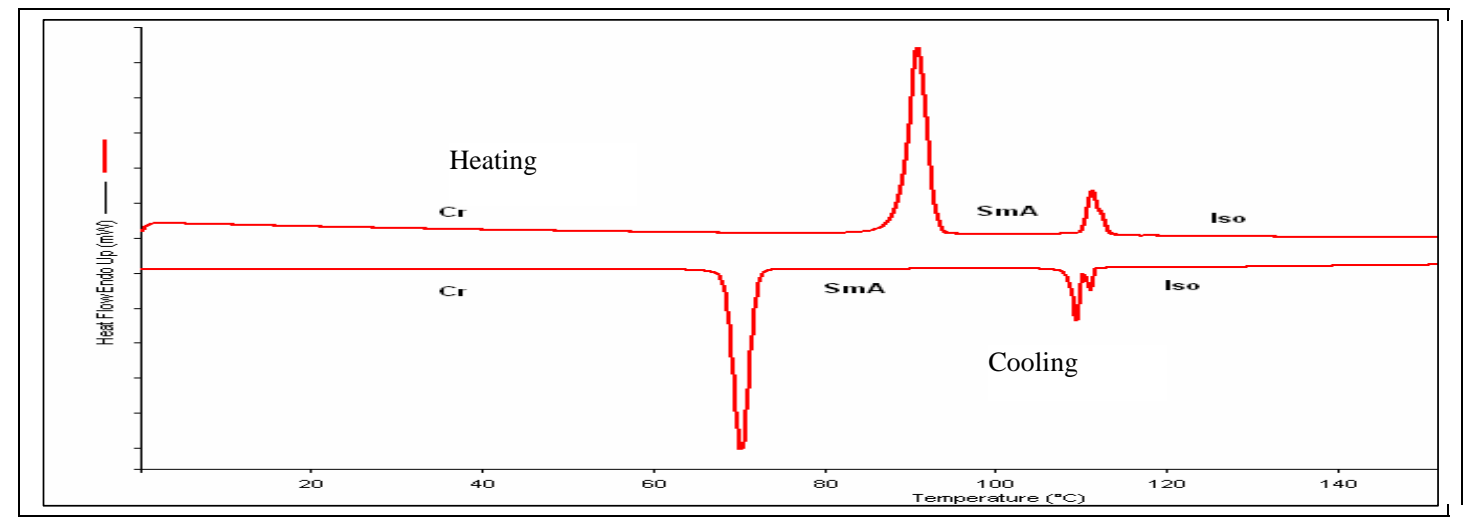

Figure 1: DSC second heating and cooling traces of compound $5 \mathrm{~b}\left(10^{\circ} \mathrm{C} \mathrm{min} \mathrm{m}^{-1}\right)$

\section{Phase structures}

The phase structures were determined by polarizing optical microscope (POM). The representative polarized optical micrograph of series of prepared compounds (5a-5e and $\mathbf{5 f}$ ) observed in the liquid crystalline phase for the second heating and cooling cycle, is shown in Figure 3 for compound $\mathbf{5 a}$ and $\mathbf{5 c}$ respectively.

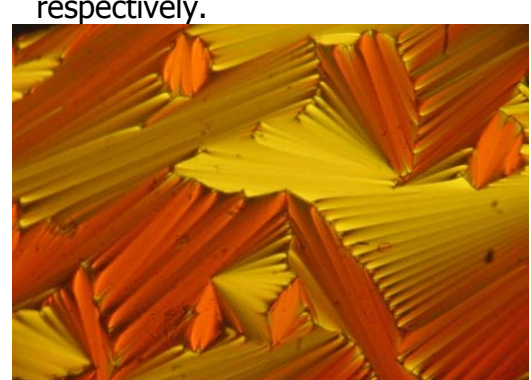

$5 b$

Figure 3: Optical photomicrograph of $5 a$ on heating to isotropic liquid at $124.2{ }^{\circ} \mathrm{C}$ and $5 \mathrm{~b}$ on cooling from the isotropic liquid at $114.2^{\circ} \mathrm{C}$ (Cross polarizer magnification $\times 200$ ). 
On heating to the isotropic phase and cooling from the isotropic phase smectic A textures were observed under the polarizing optical microscope for compounds with short to medium spacers $\left(\mathrm{C}_{2}-\mathrm{C}_{6}\right)$ Thus, exhibiting enantiotropic SmA liquid crystal phases. Compound $\mathbf{5 f}$ $\left(\mathrm{C}_{8}\right)$ shows a monotropic phase on cooling from the isotropic liquid with no mesophase on heating to isotropic liquid. The enthalpy change associated with this transition is as a result of crystal to isotropization temperature. The texture is typical of a broken Fanshaped focal-conic texture. It has been demonstrated that the presence of intermolecular hydrogen bonding of secondary amino groups and interactions between aromatic rings is expected to play an important role in molecular ordering. The aliphatic spacer would provide the mobility necessary for molecular arrangement into an ordered smectic structures (Goldmann et al. 1998).

\section{X-ray diffraction studies}

The Smectic structures of the liquid crystal phases were confirmed by XRD studies. The representative Xray pattern of the Smectic $A$ form recorded at $80{ }^{\circ} \mathrm{C}$ for compound $\mathbf{5 b}$ contains a diffuse band at $4.4 \mathrm{~A}^{\circ}$ (wide angle), which shows that the alkyl chains have a liquid-like structure and are segregated from the aromatic cores. However, the presence of two sharp reflections at 33.73 and $16.22 \mathrm{~A}^{\circ}$ (small angle) in a ratio of $1: 2$ indicates unambiguously the presence of layers (Kouwer et al., 2002).

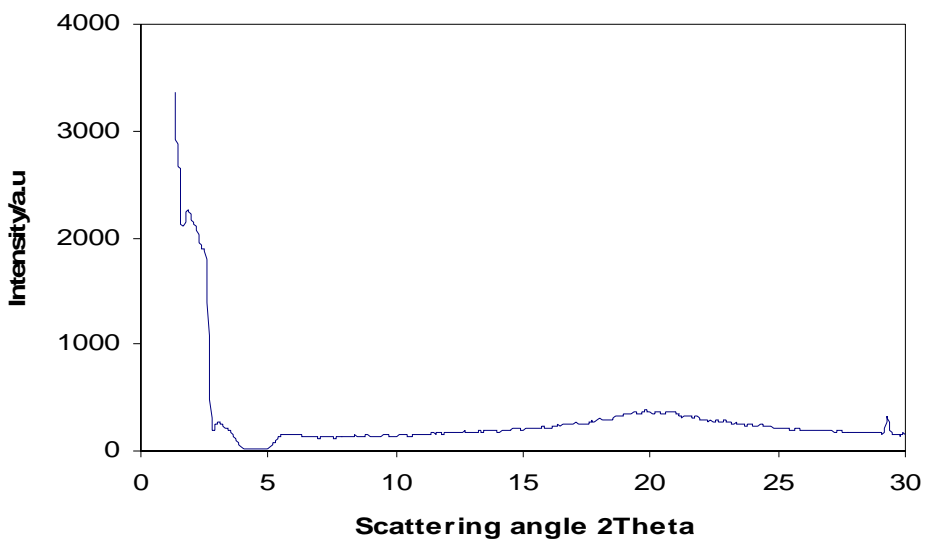

Figure 3: Powder X-ray diffraction pattern of compound 4 in the liquid crystal state $\left(80{ }^{\circ} \mathrm{C}\right)$

It has been shown previously that a parallel arrangement of at least two rod-like sub-units is most preferable for liquid crystalline oligomers with three or four mesogenic moieties attached to the same central linking compound like compounds (5a- $\mathbf{5 d}$ and $\mathbf{5 f}$ ) in such a fork-like conformation [Goldman et al 1998]. If assumed this conformation, the layer distance shall be less than half of the molecular length for all the compounds studied (Figure 4). This means that, the rod-like azobenzene units determine the mesophase i.e. the Smectic layers should be formed by the rod- like units and the core 1,3,5-triazine units act only as linking unit interconnecting the rods. It is assumed that the aromatic rod-like cores are organized in common layers together with the disc-like 1,3,5triazine core. The spacer units are located within the aromatic sublayers and form sublayers with a reduced concentration of the azobenzene segments. In such an arrangement, the layer spacing is amounting to value between $1 / 3$ and $1 / 2$ of the total molecular length $L$, depending on the degree of intercalation of the azobenzene moieties (Lutfor et al. 2005).

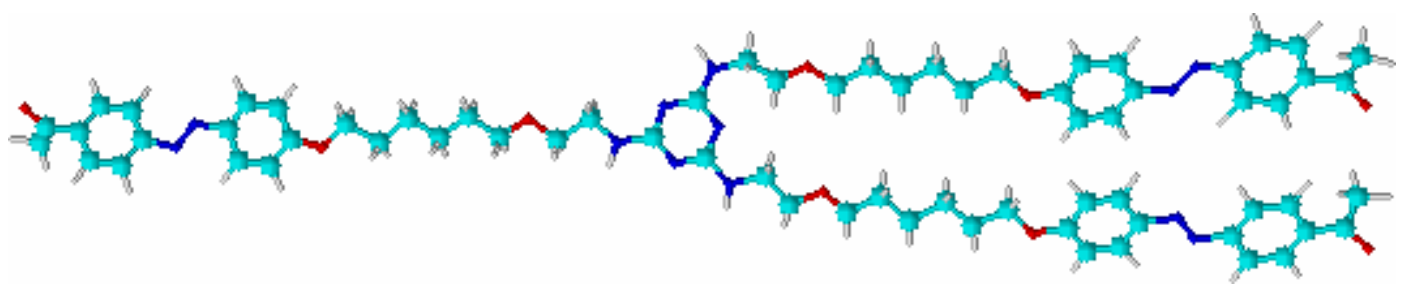

Figure 4: 3D Optimized molecular model of compound 5 representative of the series where, 1,3,5triazine central core is linked to three azobenzene moieties as the peripheral units

Lutfor et al. (2005) described a related azobenzene with triphenylene as central core, where the smectic layer is reported to be formed by the rod-like azobenzene units and the triphenylene unit act only as linking unit interconnecting the rods. In compound $\mathbf{5}$, the 1,3,5-triazine core and peripheral azobenzenes are linked by more flexible spacers (hexamethylene and ethylene via ether linkage, no semi rigid -COO group) which allows a much easier conformational change. Thus, the rod-shaped part can easily align parallel to form a smectic layer structure. 


\section{Conclusion}

New series of disc-shaped liquid crystal molecules were prepared based on 1,3,5-triazine central core, and three rod-like azobenzenes as the peripheral arm units connected through alkyl spacers via secondary amino linkages. Increase in the polymethylene spacer length influence the thermal and phase stability of these compounds. The substitution pattern through alkyl spacer units lead to the formation of wellordered Smectic A phase due to the assembly of the mesogenic rod-shaped azobenzene parts. The 1,3,5triazine core seems only to be linking unit,

\section{REFERENCES}

Furumi, S., Kidowaki, M., Ogawa, M., Nishiura Y. and K. J. Chimera (2005) Surface mediated photoalignment of discotic liquid crystals on azobenzene polymer films Journal of Physical Chemistry, 109: 92459254.

Goldmann, D. Janietz, D.Festag, R., Schmidt, C. and Wendorff, J.H. (1996) New disc shaped triarylamino-1,3,5-triazines with hetroaromatic central core, Liquid crystals 21: 619.

Goldmann, D. Janietz, D., Schmidt, C. and Wendorff, J.H. (1998) Liquid crystalline 1,3,5-triazines incorporating rod-like azobenzene subunits, Liquid Crystals. 25: (6) 711-719.

Kouwer, P. H. J., Jager, W. F., Mijs W. J., Picken S. J. (2003) Specific interactions in discotic liquid crystals, Journal Material Chemistry, 13: 458-469.

Kouwer, P. H. J. (2002). Mesophase formation in discotic liquid crystalline polymers,

Netherlands, Delft University Press, PhD Thesis, 2950.

Lee C. J., Lee S. J. and Chang J. Y. (2002). Synthesis of a polymerizable discotic liquid crystalline compound with a 1,3,5-triazine core, Tetrah. Lett. 43: 3863-3866.

Lee C. H. and Yamamoto T., (2001). Synthesis and characterization of a new class of liquidcrystalline, highly luminescent molecules containing a 2,4,6-triphenyl-1,3,5-triazine unit, Tetrah. Lett. 42: 3993-3996.

Lee H., Kim D., Lee H. K., Qiu W., Oh N. K., Zin W. C. and Kim K., (2004). Discotic liquid interconnecting the rod-like (oligomer effect) rather than a disc-like unit, which might have lead to columnar organization.

\section{Acknowledgement}

This work was supported by the Department of Chemistry Universiti Putra Malaysia. Sincere thanks goes to the Bayero University Kano, Nigeria for offering study fellowship, McArthur Grant [82511] and the Kano state Government of Nigeria for financial support.

crystalline materials for potential nonlinear optical applications: synthesis and liquid crystalline bahavior of 1,3,5-triphenyl2,4,6-triazine derivatives containing achiral and chiral alkyl chains at the periphery, Tetrah. Lett. 45: 1019-1022.

Lutfor, M. R., Tshierske C., Yusoff, M. and Sidik, S., (2005) Synthesis and liquid crystalline properties of a disc-shaped molecule with azobenzene at the periphery, Tetrahedron Letters 46: 2303-3606

Lutfor, M. R., Yusoff, M., Tshierske, C., Pelz, K., Baumeister U. and Sidik, S., (2005) Nematic and Smectic Mesophase formation by a Novel Triphenylene-Azobenzene Hybride, Molecule, Electronic liquid crystal communication:

at http://www.e.lc.org/docs/2005 062621 $47 \quad 19$

Liu J., Zhang Q. and Zhang J., (2005) Synthesis and characterization of photochromic star-like liquid crystal, Materials Letters 59: 2531 2534.

Salisu A. A. (2008) Synthesis and mesomorphic properties of a disc-shaped 1,3,5-triazine liquid crystal containing azobenzene at the peripheral arms, Int. Jor. P. App. Scs. 2(3):119-124.

Yildirim Z., Wubbenhost M., Mendes E., Picken S. J., Paraschiv I., Marcelis A. T. M., Zuilhof $H$. and Sudholter E. J. R. (2005) Multiple glass transitions in the plastic crystal phase of triphenylene derivatives. Journal of NonCyrstalline Solids, Article in press. 